\title{
Reliability analysis of rainwater tanks using daily water balance model: variations within a large city
}

\begin{abstract}
A daily water balance model is used for the performance analysis and design optimisation of rainwater tanks at four different regions of Melbourne; North, Central, South-East and SouthWest. These four different regions of Melbourne are characterised by notable different topography and rainfall characteristics. From historical rainfall data, three representative years (dry, average and wet) are selected. Reliability is defined as percentage of days in a year when rainwater tank is able to supply the intended partial demand for a particular condition. For the three climatic conditions, a number of reliability charts are produced for domestic rainwater tanks in relation to tank volume, roof area and number of people in a house (i.e. water demand). It is found that for a relatively small roof size $(100 \mathrm{~m} 2), 100 \%$ reliability cannot be achieved even with a very large tank $(10,000 \mathrm{~L})$. Reliability becomes independent of tank size for tank sizes larger than 4000-7000 L depending on the location. This is defined as threshold tank size, relationships with threshold tank sizes and annual rainfall amounts are then established for all the locations. A new factor named 'Rainwater Accumulation Potential (RAP)' has been introduced and maximum achievable reliabilities for different reasonable RAPs under different climatic conditions are presented for all the locations selected in this study. From these findings, for the design of rainwater tank size it is recommended to have a RAP value of $0.8-0.9$ for greater Melbourne.
\end{abstract}

Keyword: Rainwater tank; Daily water balance; Climatic conditions; Reliability; Threshold tank size 